\title{
The effect of colloid and crystalloid preloading on thromboelastography prior to Cesarean delivery
}

\author{
[L'effet d'une précharge avec un colloïde ou un cristalloïde sur le thromboélasto- \\ gramme avant l'accouchement par césarienne]
}

Alexander Butwick FRCA, Brendan Carvalho MBBCh FRCA

Purpose: Fluid preloading with colloids reduces hypotension after spinal anesthesia for Cesarean delivery more effectively than crystalloids. However, the effects of fluid preloading regimens on coagulation in pregnant patients remain unresolved. The aim of this study was to compare the effects on coagulation of fluid preloading with $6 \%$ hydroxyethyl starch (HES) and lactated Ringer's (LR) solution using thromboelastography (TEG) with kaolin-activated whole blood in healthy pregnant patients prior to spinal anesthesia for Cesarean delivery.

Methods: After obtaining Ethics committee approval, 30 parturients were prospectively randomized prior to spinal anesthesia for elective Cesarean delivery to receive fluid preloading with either $1500 \mathrm{~mL}$ LR or $500 \mathrm{~mL} 6 \%$ HES over $30 \mathrm{~min}$. Thromboelastography was performed immediately prior to and after fluid preloading. Standard TEG parameters were analyzed in terms of $r$ time ( $\mathrm{min}), \mathrm{k}$ time ( $\mathrm{min}), \alpha$ angle (degrees) and maximum amplitude $(\mathrm{mm})$.

Results: Group HES had statistically significant longer reaction times $(r)$ and clot formation times ( $k$ ) after fluid loading compared to baseline values $(P<0.05$ respectively), although these post-fluid loading TEG parameters remained within a normal reference range. No significant differences in TEG values were seen after preloading within the LR group.

Conclusion: Fluid preloading with $500 \mathrm{~mL} 6 \%$ HES in healthy parturients produced mild coagulation effects, as measured with TEG, prior to spinal anesthesia for Cesarean delivery. No significant effects on coagulation with TEG were observed following preloading with $1500 \mathrm{~mL}$ LR.

CAN J ANESTH $2007 / 54: 3 /$ pp 190-195
Objectif : La précharge liquidienne avec un colloïde plutôt qu'avec un cristalloïde réduit plus efficacement l'hypotension associée à la rachianesthésie lors de l'accouchement par césarienne. Toutefois, les effets de l'administration d'une précharge liquidienne sur la coagulation chez les patientes enceintes demeurent inconnus. L'objectif de cette étude était de comparer les effets sur la coagulation d'une précharge liquidienne avec de l'amidon hydroxyéthylé (AHE) $6 \%$ et une solution de lactate Ringer (LR) en utilisant un thromboélastogramme (TEG) avec du sang complet activé au kaolin chez les patientes enceintes saines avant la rachianesthésie pour l'accouchement par césarienne.

Méthodes : Avec l'approbation du comité d'éthique, 30 parturientes ont été prospectivement randomisées, avant la rachianesthésie pour l'accouchement par césarienne, à recevoir une précharge liquidienne de I $500 \mathrm{~mL} \mathrm{LR}$ ou $500 \mathrm{~mL}$ AHE $6 \%$ en $30 \mathrm{~min}$. Un thromboélastogramme a été effectué immédiatement avant et après l'administration de la précharge liquidienne. Les paramètres standard du TEG ont été utilisés en fonction du temps $r$ ( $\mathrm{min})$, du temps $k$ (min), de l'angle $\alpha$ (degrés) et de l'amplitude maximum ( $\mathrm{mm}$ ).

Résultats : Le groupe AHE a présenté des temps de réaction ( $r$ ) et de formation de caillots $(k)$ statistiquement plus longs après charge liquidienne en comparaison des valeurs de base $(P<0,05$ respectivement), bien que ces paramètres de TEG après charge liquidienne soient restés dans une marge de référence normale. Aucune différence significative dans les valeurs du TEG n'a été observée après précharge dans le groupe RL.

Conclusion: La précharge liquidienne avec $500 \mathrm{~mL}$ de AHE $6 \%$ chez les parturientes en bonne santé $a$ eu des effets légers sur la coagulation selon les mesures prises avec le TEG avant la rachianesthésie pour accouchement par césarienne. Aucun effet significatif sur la coagulation avec TEG n'a été observé suite à une précharge de I $500 \mathrm{~mL}$ LR.

From the Department of Anesthesia, Stanford University School of Medicine, Stanford, California, USA.

Address correspondence to: Dr. Brendan Carvalho, Department of Anesthesia, H3580, Stanford University School of Medicine, 300

Pasteur Drive, Stanford, California 94305, USA. Fax: 650-725-8544; E-mail: bcarvalho@stanford.edu

This study was conducted at Lucile Packard Children's Hospital and Stanford University School of Medicine, Stanford, California, USA.

The study was supported, in part, by a grant from the Iris F. Litt Fund (Stanford University, CA, USA).

The manufacturer of the TEG ${ }^{\circledR}$ device (Haemoscope Corporation, Niles, IL, USA) did not sponsor this study and had no involvement

in the design, execution, or data analysis. The authors have no financial interest in this technology or the company that manufactures the

$\mathrm{TEG}^{\circledR}$ device.

This study was presented in part at the Society for Obstetric Anesthesia and Perinatology (SOAP) 38th Annual Meeting, April 2006,

Miami and at the Obstetric Anaesthetists Association of Great Britain (OAA) Annual Scientific Meeting, May 2006, Glasgow.

Accepted for publication October 17, 2006.

Revision accepted November 16, 2006.

Final revision accepted November 30, 2006. 
$\mathrm{F}$ LUID preloading is advocated to reduce the incidence and severity of hypotension following spinal anesthesia for elective Cesarean delivery $(\mathrm{CD})$. Colloid preloads have been shown to be more effective in reducing the incidence of hypotension than crystalloids. ${ }^{1,2}$ Hydroxyethyl starch (HES) colloid solution is a more effective volume expander in parturients than lactated Ringer's (LR) solution due to its longer intravascular halflife. ${ }^{3}$ Previous studies have centered on the efficacy of various types of fluids for preloading prior to $\mathrm{CD}$, and limited information exists regarding the effects on coagulation of different preloading and intraoperative fluid regimens in obstetric patients undergoing spinal anesthesia for CD. ${ }^{4}$

Thromboelastography (TEG) is a real-time monitor of whole blood coagulation, and measures the viscoelastic properties of blood as well as coagulation factor and platelet activity from a single blood sample. Studies using TEG suggest that hemodilution with HES and crystalloid solutions can lead to hypocoagulable and hypercoagulable effects respectively, and these changes may vary in response to different degrees of hemodilution. ${ }^{5-10}$

Although the hypercoaguable changes associated with pregnancy have been previously demonstrated using TEG, ${ }^{11}$ limited data exist with regards to potential changes in coagulation after fluid preloading in pregnant patients. No previous studies have investigated the effects on coagulation following HES preloads in pregnant patients. The aim of this study was to evaluate the effects on blood coagulability using TEG in response to fluid preloading with $6 \%$ HES and LR in healthy pregnant patients prior to spinal anesthesia for CD.

\section{Methods}

After obtaining Ethics committee approval and written informed consent, we enrolled 30 healthy patients with uncomplicated singleton pregnancies at term (37-4l weeks gestation) presenting for elective CD under spinal anesthesia. Patients with significant medical or obstetric co-morbidity including hypertension, preeclampsia, liver disease, preexisting coagulation disorders and diabetes mellitus were excluded. In addition, patients receiving aspirin, non-steroidal antiinflammatory medications or any anticoagulant medication were excluded from the study.

After enrolment, group assignments were determined by a computer-generated number sequence and were contained in sequentially numbered opaque envelopes to ensure blinding. Patients were randomized to receive fluid preloading with either $1500 \mathrm{~mL}$
LR solution or $500 \mathrm{~mL}$ 6\% HES (average molecular weight $670 \mathrm{kd}$; molar substitution 0.75) (Hespan; Hospira, Lake Forest, IL, USA). Prior to preloading, an $18-\mathrm{G}$ peripheral iv cannula was inserted into a forearm vein and an initial blood sample was obtained for TEG analysis to provide baseline values. The first $4 \mathrm{~mL}$ of blood was discarded to avoid tissue contamination. The fluid preload was administered over $30 \mathrm{~min}$ by an anesthesiologist in the preoperative holding area. A second blood sample was subsequently taken via a 22 $\mathrm{G}$ butterfly needle from the contralateral arm using the same sampling technique. Thromboelastography analysis was performed within four minutes of blood sampling.

Thromboelastography was performed by another anesthesiologist blinded to the group randomization, using a computerized Thromboelastograph ${ }^{\circledR} 5000$ analyzer (Haemascope Corp. Niles, IL, USA) with disposable plastic cups and pins. One millilitre of whole blood was placed into a vial containing kaolin ( $40 \mu \mathrm{L}$ in $0.85 \%$ saline) and, after mixing by inversion eight to ten times, $360 \mu \mathrm{L}$ kaolin-activated whole blood was pipetted into a plastic cup in a prewarmed TEG $\left(37^{\circ} \mathrm{C}\right)$.

Standard TEG parameters were analyzed in terms of $\mathrm{r}$ time ( $\mathrm{min}), \mathrm{k}$ time $(\mathrm{min}), \alpha$ angle (degrees) and maximum amplitude (MA) ( $\mathrm{mm}$ ). The reaction time $(\mathrm{r})$ is the time from the start of recording until initial fibrin formation (amplitude $=2 \mathrm{~mm}$ in the TEG tracing); it represents the function of the clotting factors. The $\mathrm{k}$ time is measured from $\mathrm{r}$ until a fixed level of clot firmness (amplitude $=20 \mathrm{~mm}$ ); it represents the dynamics of clot formation. The $\alpha$ angle is the slope of the TEG trace from $r$ value to the $k$ value and is closely related to the $\mathrm{k}$ time; it represents the rate of fibrin build-up and cross-linking. The MA represents the ultimate strength of the fibrin clot. The underlying principles of TEG have been described in an early review article. ${ }^{12}$ Thromboelastography analysis was terminated after the MA value of the TEG pattern had been calculated. Other hematological tests performed in all patients prior to fluid preloading included hemoglobin level and a platelet count.

TABLE I Demographic and obstetric data

\begin{tabular}{lll}
\hline & LR $(n=14)$ & HES $(n=16)$ \\
\hline Age $(\mathrm{yr})$ & $35 \pm 6$ & $33 \pm 5$ \\
Weight $(\mathrm{kg})$ & $80 \pm 15$ & $77 \pm 10$ \\
Height $(\mathrm{cm})$ & $163 \pm 6$ & $164 \pm 8$ \\
Gestational age (weeks) & $39 \pm 1$ & $39 \pm 1$ \\
\hline
\end{tabular}

Values are presented as mean \pm SD. $P=$ not significant between the groups. LR = lactated Ringer's; HES = Hespan. 
TABLE II Thromboelastographic (TEG) data before and after preloading in the lactated Ringer's group and Hespan group

\begin{tabular}{|c|c|c|c|c|}
\hline & \multicolumn{2}{|c|}{$L R$} & \multicolumn{2}{|c|}{ HES } \\
\hline & Before preload & After preload & Before preload & After preload \\
\hline $\mathrm{r}(\min )$ & $3.7(2.9-4.0)$ & $5(3.2-5.3)$ & $4.0(2.9-4.5)$ & $5.5(3.8-6.5)^{\star}$ \\
\hline$\alpha$ angle & 70.1 & 71.7 & 68.5 & 62.7 \\
\hline$\left({ }^{\mathrm{o}}\right)$ & $(67.8-74.3)$ & $(64.2-73.0)$ & $(64.3-72.9)$ & $(58.4-70.6)$ \\
\hline MA & 79.7 & 80.2 & 76.2 & 74.0 \\
\hline
\end{tabular}

Data presented as median (interquartile range). ${ }^{\star} P=0.01$ vs baseline; $\dagger P=0.004$ vs baseline; ${ }^{\ddagger} P=0.002$ vs LR after preload. $\mathrm{r}=$ reaction time (normal range, $4-8 \mathrm{~min}$ ), $\mathrm{k}=$ clot formation time (normal range, $1-4 \mathrm{~min}$ ), $\alpha$ angle $=$ clot formation rate $\left(\right.$ normal range, $47^{\circ}-74^{\circ}$ ). $\mathrm{MA}=$ maximum amplitude (normal range, 55-73 mm); LR = lactated Ringer's; HES = Hespan.

\section{Statistical analysis}

Based on data from previous in vivo TEG studies assessing hemodilution with crystalloids and colloids, ${ }^{6,8,13,14}$ we predicted that a sample size of 15 patients in each group would be necessary to detect a $30 \%$ difference in $\mathrm{r}$ time (power $0.8, P<0.05$ ) between study groups. Data are presented as mean $( \pm$ $\mathrm{SD})$ or median (interquartile range) where appropriate. Analysis was performed with use of the SPSS 11.0 for Windows statistical package (Chicago, IL, USA). Data were assessed for normal distribution of variance using normality plots and the Kolmogorov-Smirnov test. Normally and non-normally distributed TEG parameters before and after preloading for each group were assessed using the paired $t$ test and Wilcoxon signed-rank test respectively. The unpaired $t$ test and Mann-Whitney U test, where appropriate, were used for intergroup comparisons of the changes in TEG variables. Multiple comparisons (between-group and within-group) of each TEG coagulation parameter were performed, therefore a more conservative $P$ value $<0.025$ was considered statistically significant.

\section{Results}

All 30 patients completed the study according to protocol and were included in the analysis. The unequal distribution of patients in the study groups (14 patients in group LR and 16 patients in group HES) was due to the sequence of computer-generated randomization. No subjects were withdrawn or lost to follow-up during the study. Demographic and baseline obstetric characteristics were similar among treatment groups (Table I). The hemoglobin in the LR group was $12.5 \pm 1 \mathrm{~g} \cdot \mathrm{dL}^{-1}$ and in the HES group was $12.7 \pm 0.7 \mathrm{~g} \cdot \mathrm{dL}^{-1}(P=0.75$ between groups $)$. The mean platelet count in the LR group was $231 \pm 54 \times$ $10^{9} \cdot \mathrm{L}^{-1}$ and in the HES group was $224 \pm 43 \times 10^{9} \cdot \mathrm{L}^{-1}$ ( $P=0.95$ between groups).

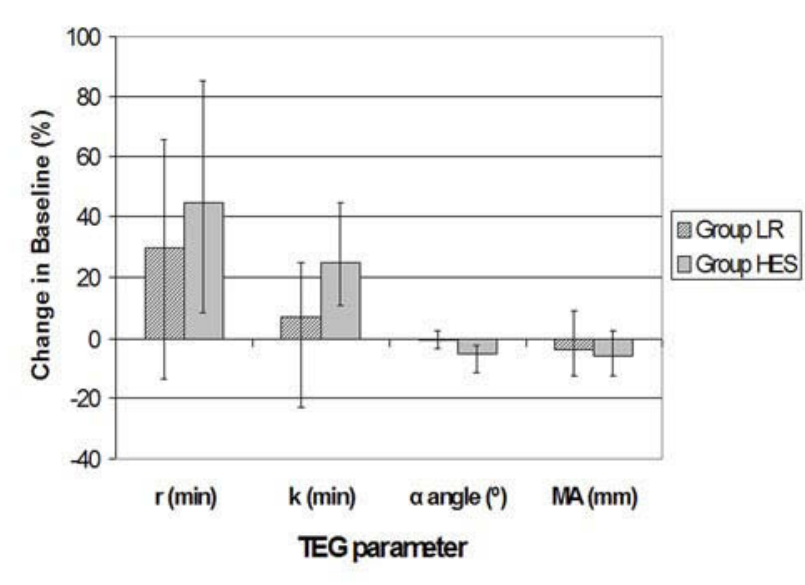

FIGURE Percentage change from baseline values for TEG data in the LR and HES group. Data presented as median (interquartile range). TEG = thromboelastographic; $\mathrm{LR}=$ lactated Ringer's; HES = Hespan.

\section{Thromboelastography parameters}

Baseline TEG values were similar between the two groups. There were statistically significant increases in $\mathrm{r}$ time $(P=0.01)$ and $\mathrm{k}$ time $(P=0.004)$ in the HES group after preloading compared with baseline values, however these values remained within a normal reference range (Haemascope Corp. Niles, IL, USA) (Table II). No significant differences in $\mathrm{r}$ time $(P=$ $0.21)$ and k time $(P=0.67)$ were found after preloading in the LR group. The $\mathrm{k}$ time was significantly higher in the HES group after preloading compared to the LR group ( $1.7 \mathrm{~min}$ vs $1.2 \mathrm{~min}$ respectively; $P$ $=0.002)$, although both values remained within a normal reference range (Table II). The percentage changes from baseline in TEG parameters before and after preloading were also calculated for both groups (Figure). 


\section{Discussion}

Our results suggest a mild hypocoagulable effect relative to baseline values with TEG following preloading with $500 \mathrm{~mL} 6 \%$ HES in pregnant patients prior to spinal anesthesia for elective CD. In contrast, we found no significant differences in TEG parameters after crystalloid preloading with $1500 \mathrm{~mL}$ LR.

Physiological changes during pregnancy result in increased platelet aggregation and coagulation factors (II, VII, VIII, IX, X, XII and XIII), decreased endogenous anticoagulants (protein $\mathrm{C}$ and $\mathrm{S}$ ) and modified fibrinolytic capacity. ${ }^{15}$ These pregnancy-associated changes result in a hypercoagulable state as compared with the non-pregnant state. Thromboelastography has demonstrated that post-partum patients remain hypercoaguable in the first $24 \mathrm{hr}$ following delivery. ${ }^{11}$ The baseline TEG values in our study are in keeping with previously described TEG changes associated with pregnancy (shortened $\mathrm{r}$ and $\mathrm{k}$ times, and relatively increased MA and $\alpha$ angle) relative to normal values for kaolin-activated TEG (Table II). ${ }^{11}$

Fluid preloading has become routine practice prior to spinal anesthesia for CD to attenuate associated hypotension caused by the reduction in systemic vascular resistance and the increase in venous capacitance. Colloids, in particular HES, appear to be more effective than crystalloids at preventing hypotension in this setting, ${ }^{1,2}$ and this is due to the longer half-life of HES in the intravascular space. ${ }^{3}$ However, there is limited data comparing changes in coagulation following fluid preloading in this patient population.

We found statistically significant increases in TEG parameters ( $\mathrm{r}$ and $\mathrm{k}$ times) following HES preloading, however these post-fluid loading TEG parameters remained within the normal reference range (Haemascope Corp. Niles, IL, USA). These observed differences appear to be small, but our study had adequate power to detect this degree of change following fluid preloading. The potential effects of these coagulation changes on clinical outcomes remain unclear, and confirmatory in vivo studies are necessary to further assess the effects on coagulation of different fluid preloading regimens.

Previous in vivo and in vitro TEG studies have demonstrated that HES hemodilution $(\geq 20 \%)$ may compromise coagulation in non-obstetric patient populations. ${ }^{5,7-9,16,17}$ Hemodilution with slowly-degradable HES decreases circulating factor VIII and von Willebrand factor (vWF) resulting in a hypocoagulable state at mild to moderate hemodilutions. ${ }^{18}$ In addition, HES has inhibitory effects on platelet function (by reducing activity or reducing binding to the platelet fibrinogen receptor glycoprotein IIb-IIIa). ${ }^{18}$
Previous studies have reported that HES with high molecular weight and a high degree of molar substitution (DS) have greater effects on hemostasis than equivalent low molecular weight HES with lower DS. ${ }^{16,19}$ The differences between the individual pharmacokinetic characteristics of HES preparations may be important, as recent evidence suggests that higher DS may compromise coagulation more than lower DS with high-molecular weight HES solutions. ${ }^{20}$

We observed no significant differences in TEG parameters after LR preloading in our study. These results are similar to those reported by Sharma and colleagues who found no significant differences in TEG parameters between patients receiving 1000 $\mathrm{mL}$ LR preload prior to spinal anesthesia for CD and patients prior to general anesthesia for CD with no fluid preloading. ${ }^{4}$ However, in vivo and in vitro TEG studies in non-obstetric populations suggest that hypercoagulable changes may occur following crystalloid hemodilution, and these effects may vary according to the degree of percentage hemodilution with crystalloid. ${ }^{6,8,13,21}$ Quantitative and qualitative changes in thrombin generation and other important anticoagulants (such as anti-thrombin III) in pregnancy may play a role in enhancing coagulation with crystalloid hemodilution. ${ }^{15}$

Previous studies have postulated that TEG changes may correlate with obstetric morbidity. Elevated prepregnancy MA has been associated with an increased risk of miscarriage, ${ }^{22}$ and strong correlations have also been shown between MA and low platelet counts in patients with severe preeclampsia. ${ }^{23,24}$ However, there is limited data comparing changes in coagulation following fluid preloading in pregnant patients. Gorton and colleagues compared TEG changes following preloading with $500 \mathrm{~mL}$ gelofusine prior to $\mathrm{CD}$ with a group of patients who did not receive fluid preloading. ${ }^{14}$ The authors reported similar hypercoagulable changes in both study groups, however no absolute values were given, thus limiting interpretation. Previous studies have suggested different gelatin solutions are associated with variable effects on coagulation. ${ }^{7,9,10}$ A previous in vivo TEG study assessing coagulation in the pre- and postanesthesia periods in patients undergoing CD (with spinal anesthesia and $1000 \mathrm{~mL}$ LR preload) reported no significant differences in any TEG parameter. ${ }^{4}$ Unfortunately, intraoperative fluids were not standardized in this study which may have influenced postanesthesia TEG values.

We acknowledge that there are several limitations to our study. We did not investigate the degree of hemodilution associated with each preload. However, the preload volumes used in our study $(1500 \mathrm{~mL} \mathrm{LR}$ solu- 
tion vs $500 \mathrm{~mL} 6 \% \mathrm{HES}$ ) were based on results from a previous study which demonstrated that these regimens increase the blood volume of pregnant patients prior to $\mathrm{CD}$ to a similar degree ( $8 \%$ vs $10 \%$ respectively). ${ }^{3}$ Further, our study was specifically designed to assess TEG changes in response to fluid preloading prior to CD. Thromboelastography has become a sophisticated method of assessing the dynamic properties of coagulation in vivo and in vitro, and also provides information of the patient's global coagulation status at the bedside or in the operating room within a short timeframe. It is likely that additional coagulation tests (including factor VIII and vWF levels) would have complemented our results. However, the decreases in plasma concentrations of factor VIII and vWF following HES infusion may not necessarily reflect similar alterations in individual clotting factor functional activity, and the specific mechanisms of impaired clotting function induced by HES remain unclear. ${ }^{18}$ Finally, our blood sampling technique differed before and after preloading which may have affected TEG analysis. However, a previous study has suggested separate blood sampling via a cannula or venepuncture does not ultimately alter the TEG pattern. ${ }^{8}$

Hydroxyethyl starch solutions vary in terms of their molecular weight, DS and $\mathrm{C} 2 / \mathrm{C} 6$ ratio, and these physicochemical characteristics may individually affect blood coagulation. ${ }^{20}$ Further investigations to compare the effects on coagulation of different fluid preloading and intraoperative fluid regimens during $\mathrm{CD}$ are warranted. It is possible that the hypercoagulable state normally seen in the post-operative period, as a result of the acute phase response to surgery, may be attenuated by HES solutions. ${ }^{18}$ In vivo coagulation studies are necessary to assess potential associations between perioperative fluid regimens and important clinical outcomes post-CD (thromboembolic events, blood loss).

In conclusion, TEG showed that preloading with $500 \mathrm{~mL} 6 \%$ HES is associated with a mild hypocoagulable effect in healthy parturients presenting for elective CD, but post-fluid loading TEG parameters following the HES preload remained within a normal reference range. No significant differences in TEG values were seen after preloading with $1500 \mathrm{~mL} \mathrm{LR}$. Further studies are warranted to assess the coagulation effects of other fluid preloading regimens and potential effects on clinical outcomes for patients undergoing $\mathrm{CD}$ with spinal anesthesia.

\section{Acknowledgements}

We sincerely thank Dr. S.E. Cohen and Dr. P. van der Starre for their valuable input with the study methodology and manuscript preparation.

\section{References}

1 Morgan PJ, Halpern SH, Tarshis J. The effects of an increase of central blood volume before spinal anesthesia for cesarean delivery: a qualitative systematic review. Anesth Analg 2001; 92: 997-1005.

2 Riley ET, Coben SE, Rubenstein AJ, Flanagan B. Prevention of hypotension after spinal anesthesia for cesarean section: six percent hetastarch versus lactated Ringer's solution. Anesth Analg 1995; 81: 838-42.

3 Ueyama H, He $\Upsilon L$, Tanigami H, Mashimo T, Yoshiya I. Effects of crystalloid and colloid preload on blood volume in the parturient undergoing spinal anesthesia for elective cesarean section. Anesthesiology 1999; 91: 1571-6.

4 Sharma SK, Philip J. The effect of anesthetic techniques on blood coagulability in parturients as measured by thromboelastography. Anesth Analg 1997; 85: $82-6$.

5 Jamnicki M, Bombeli T, Seifert B, et al. Low- and medium-molecular-weight hydroxyethyl starches: comparison of their effect on blood coagulation. Anesthesiology 2000; 93: 1231-7.

$6 \mathrm{Ng} \mathrm{KF}$, Lam CC, Chan LC. In vivo effect of haemodilution with saline on coagulation: a randomized controlled trial. Br J Anaesth 2002; 88: 475-80.

7 Egli GA, Zollinger A, Seifert B, Popovic D, Pasch T, Spahn DR. Effect of progressive haemodilution with hydroxyethyl starch, gelatin and albumin on blood coagulation. Br J Anaesth 1997; 78: 684-9.

8 Ruttmann TG, James MF, Aronson I. In vivo investigation into the effects of haemodilution with hydroxyethyl starch $(200 / 0.5)$ and normal saline on coagulation. Br J Anaesth 1998; 80: 612-6.

9 Petroianu GA, Liu J, Maleck WH, Mattinger C, Bergler $W F$. The effect of in vitro hemodilution with gelatin, dextran, hydroxyethyl starch, or Ringer's solution on thrombelastograph. Anesth Analg 2000; 90: 795-800.

10 Ruttmann TG, James MF, Viljoen JF. Haemodilution induces a hypercoagulable state. Br J Anaesth 1996; 76: 412-4.

11 Sharma SK, Philip J, Wiley J. Thromboelastographic changes in healthy parturients and postpartum women. Anesth Analg 1997; 85: 94-8.

12 Mallett SV, Cox DJ. Thrombelastography. Br J Anaesth 1992; 69: 307-13.

13 Ruttmann TG, James MF, Wells KF. Effect of $20 \%$ in vitro haemodilution with warmed buffered salt solution and cerebrospinal fluid on coagulation. Br J Anaesth 1999; 82: 110-1.

14 Gorton H, Lyons G, Manraj P. Preparation for regional anaesthesia induces changes in thrombelastography. $\mathrm{Br}$ J Anaesth 2000; 84: 403-4.

15 Holmes VA, Wallace JM. Haemostasis in normal preg- 
nancy: a balancing act? Biochem Soc Trans 2005;

33(Pt 2): 428-32.

16 Boldt J, Haisch G, Suttner S, Kumle B, Schellhaass A.

Effects of a new modified, balanced hydroxyethyl

starch preparation (Hextend) on measures of coagulation. Br J Anaesth 2002; 89: 722-8.

17 Dailey SE, Dysart CB, Langan DR, et al. An in vitro study comparing the effects of Hextend, Hespan, normal saline, and lactated ringer's solution on thrombelastography and the activated partial thromboplastin time. J Cardiothorac Vasc Anesth 2005; 19: 358-61.

18 Kozek-Langenecker SA. Effects of hydroxyethyl starch solutions on hemostasis. Anesthesiology 2005; 103: 654-60.

19 Strauss RG, Pennell BJ, Stump DC. A randomized, blinded trial comparing the hemostatic effects of pentastarch versus hetastarch. Transfusion 2002; 42: $27-36$.

20 von Roten I, Madjdpour C, Frascarolo P, et al. Molar substitution and $\mathrm{C} 2 / \mathrm{C} 6$ ratio of hydroxyethyl starch: influence on blood coagulation. Br J Anaesth 2006; 96: 455-63.

21 Ruttmann TG, James MF, Finlayson J. Effects on coagulation of intravenous crystalloid or colloid in patients undergoing peripheral vascular surgery. $\mathrm{Br} \mathrm{J}$ Anaesth 2002; 89: 226-30.

22 Rai R, Tuddenham E, Backos $M$, et al. Thromboelastography, whole-blood haemostasis and recurrent miscarriage. Hum Reprod 2003; 18: 2540-3.

23 Sharma SK, Philip J, Whitten CW, Padakandla UB, Landers DF. Assessment of changes in coagulation in parturients with preeclampsia using thromboelastography. Anesthesiology 1999; 90: 385-90.

24 Orlikowski CE, Rocke DA, Murray WB, et al. Thrombelastography changes in pre-eclampsia and eclampsia. Br J Anaesth 1996; 77: 157-61. 